Published online 05 24, 2021

ISSN 2763-5392

\title{
The Implications of Generalized Anxiety Disorder (GAD) in contemporary women's triple shift workday
}

\author{
Alzirene Andrade da Fonseca ${ }^{1 *}$; Fabiane Gonçalves ${ }^{2}$ \\ 1 Bachelor's degree in Psychology at FACHO (Faculty of Human sciences of Olinda). \\ 2 Master in Cognitive Psychology from the Federal University of Pernambuco. She is an Adjunct Professor in the Department of Psychology \\ at the Faculty of Human Sciences of Olinda. He has experience in Psychology, with emphasis on Cognitive and Clinical Psychology, working \\ mainly on the following topics: Language, Body, Gender, Development and Culture
}

E-mail adresses: alziandrade@yahoo.com.br (Alzirene Andrade da Fonseca), fabianemsg@facho.br (Fabiane Mônica Gonçalves), ${ }^{*}$ Corresponding author

\section{To cite this article:}

Fonseca, A. A; Gonçalves, F.M. The Implications of Generalized Anxiety Disorder (GAD) in contemporary women's triple shift workday. International Journal of Sciences. Vol. 1, No. 3, 2021, pp. 55-60. ISSN 2763-5392

Received: 05 05, 2021; Accepted: 05 09, 2021; Published: 05 24, 2021

\begin{abstract}
This article presents a theoretical discussion that is based on the findings made in a work of completion of undergraduate course in the area of Psychology, aiming at the presentation of implications of Generalized Anxiety Disorder in the triple working day of contemporary women. The basis of the research was the bibliographic review with narrative, discursive and qualitative approach, which, in recent decades, has proposed the understanding and evolution of women through struggles and achievements in the labor market. The theoretical discourse has three main milestones: Clara Araujo and Maria Scalon, bring the insertion of women in work and their social conquest. Luria presents the perspective of Neuropsychology in brain dynamics and human behavior and, Judith Beck, the relationship of therapist and patient. The results describe the burden of tasks that women occupy, becoming prone to develop emotional disorders associated with stress, anxiety and depression caused, above all, by physical and psychic overload in the triple working day. Therefore, a complex look emerges that appears mainly in the context of contemporary women, affected by such psychological and physical sufferings. All this directly implies the reorganization of automatic thoughts, central and intermediate beliefs.
\end{abstract}

Keywords: Work. Woman. Generalized Anxiety Disorder. Neurocognitive Techniques.

\section{Introduction}

This article proposes a theoretical discussion based on research conducted by authors that evidence literature and narratives about the state of life of contemporary women based on their postmodern historicity. This is a bibliographic section that highlights the theoretical articulation between the authors: Costa mentions the impacts of work on the subjectivity of women and their family reactions. There is a contribution that demystifies the idea of the father figure as a provider and head of family and the woman only as a housewife; Hamdan and Pereira, in the work Neuropsychological Evaluation of Executive Functions to understand that Generalized Anxiety Disorder can affect the cognitive of the individual; Neufeld and Cavenage, based on the text: proposal of systematization from the clinical practice and training of behavioral cognitive therapists, written in the Brazilian Journal of Cognitive Therapies, the text gives the reader access to identify the three levels of cognitions identified by Cognitive Behavioral Therapy (CBT) in clinical practice.

We present, above all, the possible risks of psychological suffering and mental illnesses of contemporary women in a triple working day; we also want to conceive generalized anxiety disorder (GAD) from the perspective of Neuropsychology to understand brain dynamics and human behavior and, finally, to present Cognitive Behavioral Therapy (CBT) and its intervention proposals.

However, women who are victims of Anxiety Disorder may be marked by difficult situations to reconcile, in their daily lives, such as the triple working day. Often, women who were outgoing and became introverted, quiet and without concrete goals for experiencing this evil pass unnoticed in the eyes of common sense. They often go into depression and even commit suicide because they cannot live well with themselves and others. In this sense, the study aims to investigate the implications of Generalized Anxiety Disorder in the triple working hours of contemporary women. 


\section{The evolution of work: the challenges of women}

According to Costa (2018), the woman's work was present in all times and places, in fact she always worked, although she did not exercise "profession". The woman in Brazil in the eighteenth century was seen as "owner of the house", the one whose obligation was to take care of her husband, children, relatives and keep the house in order. However, the demands suffered by the woman by the man did not allow the work she did to be called work. For, the work outside the house was socially attributed to the man, so that it was the husband's role to ensure the support of the family, being the strong and valuable sex in the relationship.

In line with Costa (2018), the possibility of access to education for women began to have the opportunity of something different in social life. She, in turn, begins to take an interest in the school and in the convents where music and the Latin language were taught. The first normal schools appear at the end of the 19th century in Brazil, with the aim of preparing girls for teaching, considering that they were the only professions authorized for women - that of teacher and nurse for those who had the opportunity to be educated, others of domestic, workers, seamstresses and telephone operators for women belonging to the poorest layers.

With industrialization, there is a need for manpower and, with the technical, scientific, technological progress, of the great growth of machinery. Most of the workers were taken to the factories for cheap labor. Costa (2018) stresses that the family model based on the father figure as a provider and head of family and, in the woman, who owns a housewife, begins to undergo changes, if not, to collapse. For the middle-class woman to leave the house, it was necessary that someone else could replace household and childcare. That's where the profession comes from: from home.

According to Probst (2003), since the 20th century, there has been a significant increase in women's participation in the labor market. This happened due to the great growth of the industry, providing a scenario for female insertion. At the time of its insertion, there was prejudice, discrimination and gender inequality that lasted to this day. Consequently, the Constitution of 1932 in Art. 1 established that "Without distinction of sex, to all work of equal pay." Like, the Federal Constitution of 1988 in Article $5 \S$ I "men and women are equal in rights and obligations in terms of this Constitution". provides that all people, regardless of their gender, are equal from the perspective of the Constitution.

However, even with laws assisting women, they continued to be exploited, with the justification that the man was the maintainer of the home, so it was not necessary to pay a higher salary to the woman

\section{The contemporary woman: the triple working day}

The context of women in contemporary society is still going through a moment of transition. According to Bruschini (2007), circumstance concerns economic and political factors and female stereotypes that were historically created and positioned women in confrontation with the situation of inferiority. Even so, Brazilian society worships false myths, fantasies and ideas about the possibilities and potentialities of women's work. The workers, who, by the end of the 1970s, were mostly young, single and childless, became older, married and mothers. In 2005, the highest rate of female activity $74 \%$ is found among women aged 30 to 39 years, $69 \%$ of women aged 40 to 49 years and $54 \%$ of those aged 50 to 59 are also in full activity.

IBGE 2018 statistical data show that the responsibility for doing affects women's insertion in the labor market. In 2016 , disaggregated the country's population by sex, women devoted 18.1 hours per week to the care of people or household duties - about $73 \%$ more hours than men $(10.5$ hours per week). Whether in the whole population or in the universe of work, women are more educated than they are, but their average income is equivalent to about $3 / 4$ of men. In addition, in Brazil, $60.9 \%$ of management positions (public or private) were held by men, while only $39.1 \%$ by women in 2016.

The number of women in the workspace is relevant. The contemporary woman also has privileged spaces of opinions such as in managerial positions, in mechanical engineering, in politics, masters of work and the others, having time conditions and offering Brazilian society a work carried out with love and responsibility. However, it is appropriate that contemporary women be capable of all these and other professional achievements and knowing, despite personal and family challenges, reconciling the triple working day not as a burden, but as a choice that corroborates personal and professional fulfillment. Therefore, Santos (2011, p. 31) says that engaging in the world of work in its positive aspects represents security, independence and personal fulfillment. Paid work offers women the possibility of evolving both in the social and individual spheres.

However, despite many challenges ahead, the women's struggle remains relevant in the contemporary world and, as we see, has already won many rights not only in the labor market, but in politics and social.

\section{Psychological violence and mental illness: jobs overwhelm women}

The work overload or professional exhaustion of women in the triple working day can be aggravated by excessive service at work. Likewise, with the woman suffering from Burnout Syndrome or Professional Exhaustion Syndrome, it is a psychic disorder described in 1974 by Freudenberger, an American physician. The disorder is registered in group 24 of the ICD-11 (International Statistical Classification of Diseases and Related Health Problems) as one of the factors that influence health, among the problems related to employment and unemployment, when, in reality, the main cause of the disease is precisely overwork. Even, also, Generalized Anxiety Disorders can bring psychic symptoms in women who take a triple working day.

In addition, the accumulation of tasks, excessive collections, perfectionism and focus on work as an exclusive source of pleasure lead to physical and mental exhaustion. Instead of motivation, irritation, lack of concentration, 
nervousness, discouragement and feeling of failure arise, in addition to conflicts at work. These are indications of a cruel and difficult diagnosis that advances in hospitals, businesses, school, etc. Burnout syndrome results from prolonged stress at work, both triggered by exacerbated anxiety.

Araújo and Scalon (2005) say that through successes in the field of autonomy and social conquest, women enter an even greater level of demand, meeting the new standards that overlaps having "sculpted body", "well dressed and cared for", "updated in new trends", "successful professional", "exemplary mother", "home administrator", "happy, above all, sexually" and "well-performed woman"

However, Silva (2012) says that the painful aspects brought by overload and dissatisfaction in the professional work space help to bring out stress, phobias, depression, feeling of guilt and anguish, lack of concentration, fatigue among others that corroborate an unfavorable lifestyle led by generalized anxiety disorder (GAD). Women with overwork in the company lead to serious exhaustion caused by stress, especially when creating a routine. Also, it can cause bad attitudes of posture and even cause physiological brain disorder such as stroke, leading to impairment of behavior, affectivity, thinking and significant drop in physiological and psychic performance.

We observed that hostile feelings about the role of women in the world of work are related to the model of representation of machismo present since many centuries ago. Women, in turn, break the paradigm and opt for a new cultural and social world. However, the evolution of women in the workspace shows that much has already been achieved, but much remains to be done.

\section{The Genesis: Generalized Anxiety Disorder (TAG)}

According to Caixeta (2007), psychologist and collaborator of ATLASPSICO Magazine, the term anxiety comes from the Greek 'anshein', which means "strangle", "suffocate", "oppress". Anguish, a correlated term, originates from the Latin 'angor', meaning 'oppression' or 'shortness of breath', and 'angere', "causing panic". Such Latin words derive from the Germanic root 'angh', indicating "narrowing" or "constriction" - terms that refer figuratively to the subjective experience of anxiety. Starting from the understanding that all behavior is adaptive to the individual, whether practical or not, it is perceived that the experimentation of anxiety, during a very frequent and intense period, still assumes this characteristic, however, begins to "suffocate" and "oppress" in such a way, which goes beyond the limit of the bearable.

In line with Fernandes and Chaniaux (2010), excessive or unhealthy anxiety occurs when the person's state of life is disproportionate to the situation faced on a daily basis, such as psychosocial factors attributed to the fears, problems and anxieties of daily life, as well as the pace of life, which is currently increasingly competitive and stressful. Biological causes are due to changes in neurotransmitters that interfere with anxiety, the main ones being serotonin and gamma amino butyric acid (GABA). Silva (2012) defines anxiety as the sometimes-vague feeling that something unpleasant is about to happen. It also has the same role as stress, and this is strictly a physical component of anxiety.

According to the DSM/5 (2014), the associated characteristics that support the diagnosis for GAD or Major Depressive Disorder are: excessive anxiety and concern, occurring most days for at least six months and related to numerous events or activities (e.g. work and school performance); concern difficult to control; anxiety and worry are associated with three (or more) of the following symptoms (with at least some symptoms being present most days in the last six months): $\bullet$ restlessness or feeling of being at the limit; - get tired easily; - difficulty concentrating; • irritability; - muscle tension; - sleep disorders (difficulty starting or maintaining sleep and feeling unsatisfactory sleep). Anxiety, worry or physical symptoms cause clinically significant suffering or impairment in social, professional or other functioning (222 - Generalized Anxiety Disorder 300.02 (F41.1), p. 263).

For a contemporary woman to which she has a maternity and career, Cognitive - Comportamental therapy TCAN contribute to treating the anxious or depressive symptoms, mentioned above, arising from physical and mental exhaustion, due to work overload.

\section{Neuropsychology and Generalized Anxiety Disorder (TAG)}

Luria (1981), based on her Book Fundamentals of Neuropsychology, presents Neuropsychology as the science of the brain organization of human mental processes. Neuropsychology has also become a powerful instrument on the internal structure of psychological processes and a fundamental factor that leads to the creation of a brain-based theory.

Therefore, the specialist in Neuropsychology, Diniz (2018) says that anxiety can lead the individual to a good social performance, also defined as the exercise of defending one's own rights without, thus, hurting the rights of others with the domain of anxiety. Longing, restlessness and stress can also be a good response of the individual in performing a determined task, communication skills, civility, empathy, work and expression of positive feelings

Diniz (2018) considers that generalized anxiety is an emotion characterized by an unpleasant state of inner agitation. As well as, a form of strategy in a situation of coping with social performance. Generalized anxiety can also present numerous aversive consequences in the individual to the point of reaching high arousal. For example, the erroneous beliefs of perception and the reading difficulties that the person makes about the signs of their social environment can contribute thoughts and feelings such as: stress, anger, depression and others more. However, the problems that influence the emotional and behavioral of an individual refer to factors of social isolation, anxiety and social phobia.

It is worth mentioning that Neuropsychology, according to Hamdan and Pereira (2009), extends to more complex processes in the behavior of the individual. Therefore, it considers that Generalized Anxiety Disorder can affect the 
cognitive functioning of the individual, since attention is altered. This change in the Attentional System, which is responsible for Focused Attention and Selective Attention of visual stimulation, can be a consequence of hyperactivity of the amygdala, hindering the planning and execution of longterm goals and increasing the execution of behaviors guided by immediate goals.

For Moraes e Silva (2015), the diagnosis of anxiety disorder is made through the subjective report of the patient and can be perceived from physiological and psychic manifestations. The first is represented by the brain, by two interconnected systems, sympathetic and parasympathetic nervous system. They will be responsible for controlling the body's energy levels so that the fight and flight action is

Table 1. Common aspects of Anxiety - Physiological Symptoms and Cognitive Symptoms.

\begin{tabular}{c|l}
\hline \multicolumn{1}{c|}{ Physiological Symptoms } & \multicolumn{1}{c}{ Cognitive Symptoms } \\
\hline Increased heart rate, palpitations; & Fear of losing control, of being \\
Fainting, shortness of breath, rapid & unable to face; Fear of physical \\
breathing; Shaking and agitation: & injury or death; Fear of "going \\
Chest pressure; Nausea; Stomach & crazy"; Fear of negative evaluation \\
pain; Diarrhea; Feeling of & of others; Terrifying thoughts, \\
suffocation; Dizziness; Feeling of & images or memories; Distraction; \\
"empty head"; Sweating; Heat & Difficulty in reasoning and loss of \\
waves; Chills; Muscle tension; Dry & objectivity, etc. \\
mouth, etc. &
\end{tabular}

Clark and Beck, 2011

prepared. The second is described by patients as a subjective

Table 2. Common aspects of Anxiety - Symptoms Behavioral and Symptoms Affective.

\begin{tabular}{|c|c|}
\hline Symptoms Behavioral & Symptoms Affective \\
\hline Aggressive or harsh speech; Ideas & Nervous, tense; Excited; Scared; \\
\hline or speeches related to suicide; & Inhibition; Terrified; Irritable; \\
\hline Euphoria, apparent without cause; & Restless; Impatient, Frustrated; \\
\hline Reduced dialogue with family and & Sadness; Mood swing and \\
\hline friends; Search for security; Motor & affection, etc. \\
\hline unrest; Uncontrolled agitation; & \\
\hline movements; & \\
\hline Hyperventilation; & \\
\hline productivity; & \\
\hline Difficulty speaking, etc. & \\
\hline
\end{tabular}

Clark and Beck, 2011

experience such as: insomnia, difficulty concentrating, fatigue, shortness of breath, dry mouth, dizziness, sweating, diarrhea, cold skin, among others.

According to the authors Clark; Beck (2011), presented in his book Cognitive Therapy for Anxiety Disorders, will show in the tables below the mechanisms on symptoms caused by anxiety.
According to the authors Clark and Beck (2011), who expose the common aspects of anxiety, we sought to present the specificities of the main symptoms of GAD, in order to glue in greater visibility to the reader the diffuse physical and psychic manifestations in women affected by the disorder. Since the cause of Generalized Anxiety includes a number of genetic factors, brain chemistry and environmental stressors can contribute to its development.

\section{Intervention Proposals: Cognitive-Behavioral Therapy}

In line with Oliveira (2011), when we analyze CBT, we can identify its contribution to clinical intervention in anxiety disorder. People with high anxiety worry disproportionately about the future. His interpretations about events take great proportions, exaggerating the consequences, emphasizing the negative aspects and ignoring the positive ones.

The DSM-5 (2014, p.131) shows that "many of the anxiety disorders develop in childhood and tend to persist if not treated. Most occur more frequently in females than in males." To analyze this field of anxiety, CBT can help women affected by this symptom of chronic anxiety in the labor market to be more free from excessive worries and to free themselves from anguish, distorted ideas, to be able to solve more common problems on a daily life, to seek selfacceptance, to increase their mood, to seek positive relationships with others., personal growth, etc.

Contemporary women, as we have seen before, are exposed to increasingly complex, rapid and intense external stimuli as a result of modern life, and thus, the consequences are felt through the difficulty in maintaining serenity and waiting for events naturally. According to Amaral and Vieira (2009), we also saw that, for the current woman, work began to be part of her life, even before or during high school. However, because many women came from a lower-class family, work in her life was a necessity for survival, since she was very young.

In this universe of thought, we still present that the contemporary woman to reconcile the triple workday is able to resign of her own will from her free time. Therefore, it stops practicing some physical exercises, decreases the time of departure with children, husbands and friends, in short, it fails to fill the rest time, vacation and weekends with studies and others, thus being able to develop physical, cognitive and behavioral illness throughout its life.

According to Neufeld and Cavenage (2010), three levels of cognitions are identified by CBT in clinical practice: a) automatic thoughts: every internal stimulus (memory, corporeal sensation, etc.) or external (an event, seeing a person, etc.) triggers an emotional response; b) central beliefs: they are usually unknown by the subject himself and consist of general, global, rigid and generalized ideas for hundreds of situations that the person experiences in his dayto-day life. E.g.: a person who considers himself unintelligent to understand the book could have a belief that he was not able to understand anything and that he did not have enough intelligence to understand the author's concepts; c) intermediate beliefs: they are based on central belief. 
Indeed, Neufeld and Cavenage (2010) argue that central belief can lead the person to consider himself unintelligent. Not only, more is there an attitude that hates being incompetent and adhere rule that must strive hard to overcome, or perhaps the reverse model that it is no use to strive since it will not understand or memorize what is being said or read. In the rule, we also find assumptions that can be useful (if you try harder) or dysfunctional (no use trying). In the process, distortions of reality are also identified and directly worked on.

Beck (2013) says that at the beginning of the session it is common for the therapist to establish with the patient the therapeutic alliance, check the mood, symptoms and experiences of the patient during the past week and ask him to name the problems he most wants help to solve. The therapist should ask him to clarify the difficulties that may have appeared or problems he hopes to encounter in the coming days, weeks or months. The therapist will finally examine the self-help activities that the patient will receive with "home activities or action plan".

After the presentation of the problem(s), the professional will collect data about it, cognitively conceptualize the patient's difficulties such as specific thoughts, emotions and behaviors associated with the problem and then collectively plan a strategy. The strategy can sometimes be the objective and direct solution of the problem, evaluation of negative thinking associated with the problem or change in behavior that helped produce relief of symptoms.

According to Knapp (2004), treatment for TAG lasts from 12 to 15 individual sessions with one hour of duration with weekly frequency, except for the last two sessions, which take place frequently every two weeks. With this regulation, the woman affected by TAG, for example, participates in the therapeutic proposal with different treatment components that are directed to each of the three system but anxiety: * Cognitive - cognitive restructuring; * Behavioral - prevention of worry behavior, problem solving and time management; * Physiological - training in progressive muscle relaxation as of diaphragmatic breathing, imagination technique in a comfortable situation, progressive muscle relaxation technique among others.

Therefore, Knapp (2004) mentioned that these techniques aim to stimulate the parasympathetic autonomic nervous system to grant a sense of relaxation. It is important to point out that all the psychotherapeutic tools mentioned and others in the clinical intervention will only be successful if there is first a bond of trust and objectivity between therapist and client.

\section{Methodology}

This text makes use of a simple language to better identify the problem addressed. That is, we use as a basis the bibliographic review with narrative, discursive and qualitative approach. The search for existing production on the subject involved article research, monograph and journal in databases available in Google Scholar, books published between 2005 and 2018 and bibliographic registration.
Among the articles found, three articles, two monographs, three journals and ten books that characterized and/or discussed the theme were selected. The period of publication of the articles and books found was from 2005 to 2018, in which we sought to understand the relationship between the literatures. These bibliographic research models aimed to maintain the established standards and standards of ABNT.

We try to mention relevant points of women in today's society, specifically in the labor market with their physical and psychic implications. Moreover, we seek to highlight the work:"The impacts of work on the subjectivity of women and their family reactions", in Fabiana Costa's monograph, as well as its relevance in the subtopic. In view of this, we add new knowledge that aims to contribute to the implementation of actions aimed at the mental and behavioral health of women affected by Generalized Anxiety Disorder caused by the triple working day and that enable them to prevent illness.

\section{Results and Discussion}

Because we use a narrative review of the literature, this research sought to reflect the contemporary woman in the triple working day with the possible risks to develop, such as the case of exacerbated anxiety causing emotional disturbance. These changes that occur in a woman's mind affect her mood, reasoning, behaviors, attitudes, as well as performance, both in personal and professional life.

It can be observed that Cognitive -Behavioral Therapy (CBT) originated from Behavioral Therapy, being developed by Aaron Beck in the 1960s. It is a form of structured treatment based on the problem presented by the patient at that moment, seeking to modify distorted thoughts and, consequently, changing inappropriate behavior. It is a theoretical approach that guides the psychologist in the treatment of several disorders, among them, Generalized Anxiety Disorder (Wright; Basque; These (2008). This said, it is increasingly apparent to perceive the woman affected to feel fear and feeling of anxiety characterized by a physical and psychic malaise, which seems even like an agony or affliction. Consequently, presents constant symptoms of tensions in the body, feeling that something is on the ill of happening symptomatic picture of fear, lack of concentration, irritability, feeling of suffocation, cold skin, dizziness, nausea, among many others (Clark; Beck, 2012).

This study was limited to reflecting on the intervention techniques of Cognitive-Behavioral Therapy in a brief way. Although, it seeks to present to the reader in knowing the technical procedures used by the psychology professional. It is also emphasized that the diagnosis of anxiety disorder is made through the subjective report of the patient and perceived to "from physiological" and psychic manifestations "in confrontation with the Central Nervous System, the possibility of dealing scientifically with issues related to emotion" (Esperidião; Columbus; Monteverde et al 2007).

\section{Conclusions}


During the work, we accept the challenge of knowing the current panorama of the social demands of overloads imposed on women in triple working hours through readings and bibliographic research. From there, one of the main stimulating factors of Generalized Anxiety Disorder is excessive concern, stress routine, genetic factors and others, causing damage to physical and mental health.

It is valuable to highlight the career of women and their achievements along the trajectory of personal, family, professional, economic and social life, occupying an active space in society to this day. Despite the reports presented in this work, the situation of women in contemporary society still continues to go through a moment of transition in confrontation with the situation of inferiority imposed throughout history. In this study, we also observed that the area of Neuropsychology was favorable to understand about the relationship of the brain with the symptomatic picture of GAD in women when they assume work overload. The brain impulses caused by neurotransmitters offer behavior change. Until then, the symptomatic conditions presented in the study are intended to alert women about the need, when possible, to reduce work activities in order to favor organic homeostasis for body balance in a healthy way. However, we have seen that Neuropsychology is descended from the development of Neurosciences (brain) and Psychology (behavior). However, the varied theoretical frameworks brought effective contributions in response to the specific objective developed in the investigation of brain mechanisms in the behavior of women with Generalized Anxiety Disorder.

We considered in the course of the study that there are alternatives to mitigate and combat the signs and symptoms brought by Generalized Anxiety Disorder in women with triple working hours. For this, psychotherapy is a favorable means that will provide contemporary women affected by such psychological and physical sufferings to reorganize themselves in their automatic thoughts, their core beliefs and their intermediate beliefs.

We conclude that the study presented may contribute so that other studies can emerge in the proposed theme. However, their methods, techniques and practices brought into the work are constantly evolving because science is dynamic. Following this study, new research can contribute to the expansion of knowledge bringing deeper reflections of contemporary women, the triple working day and generalized anxiety disorder.

\section{References}

[1] AMARAL, Graziele Alves; Scallop, Adriane. The Woman and the Triple Work Day: The Art of Being Beija Flor. Monograph. São Paulo, 2009.

[2] ARAÚJO, C.; SCALON, C. Perceptions and attitudes of women and men about the reconciliation between family and paid work in Brazil. In: ARAÚJO, C.; SCALON, C. (Org.) Gender, families and work in Brazil. Rio de Janeiro: FGV Publishing House, 2005.

[3] BECK, Judith. Cognitive Behavioral Therapy. - Theory and practice. Translation: Sandra Mallmann da Rosa. Consulting, supervision and technical review. 2nd Ed. Sao Paulo. Artmed.2013.

[4] BRUSCHINI, Maria Cristiana Aranha. Work and gender in Brazil in the last ten years. Text prepared for presentation at the International Gender and Work Seminar at the Carlos Chagas Foundation - Mage/FCC - held in Brazil (São Paulo and Rio de Janeiro), from April 2 to 12, 2007. Collaboration of Cristiano Miglioranza and Arlene Martinez Ricoldi, FCC research assistants. Research Notebooks, v. 37, n. 132, p. 537-572, Sep. /Dec., 2007.

[5] CAIXETA, Vivian Cristina. Psychologist and Collaborator of the Journal of Psychology ATLASPSICO No. 04 | Oct 2007, p.6. TAG, generalized anxiety - a visceral emotion.

[6] COSTA, Fabiana Alves da. Woman, work and family: The impacts of work on the subjectivity of women and their family reactions. Minas Gerais, 2016. monograph. Submitted: 15/10/2017. Accepted: 15/05/2018.

[7] Classification of Mental and Behavioral Disorders of ICD-10: Clinical Descriptions and Diagnostic Guidelines (ICD-10). Porto Alegre-RS. Artmed; F41.2, 1993.

[8] CLARK, David A.; BECK, Aaron T. Cognitive Therapy for Anxiety Disorders. Porto Alegre-RS. Artmed, 2011.

[9] DINIZ, Leandro F. Malloy; FUENTES, Daniel; MATTOS, Paul; ABREU, Neander. Neuropsychological evaluation. 2nd Edition, Artmed Publishing House. Porto Alegre - RS, 2018, p. 25.

[10] DSM V (Diagnostic and Statistical Manual of Mental Disorders). Trad. Cláudia Dornelles, 5th ed, Porto Alegre - RS. Artmed, 2014, p. 131-189.

[11] ESPERIDIÃO, Vanderson Antônio; COLOMBO, Marilia Majeski; MONTEVERDE, Diana Toledo; MARTINS, Graciele Moraes; FERNANDES, Juliana José; ASSIS, Marjorie Bauchiglioni de; BATISTA, Rodrigo Siqueira. Neurobiology of emotions - Article, Rio de Janeiro 2007.

[12] FERNANDES, J. L. \& CHANIAUX, E. Transtornos de Ansiedade in: Cinema e Loucura - knowing mental disorders through movies. Porto Alegre - RS. Artmed, 2010.

[13] HAMDAN, Amer Cavalheiro, PEREIRA ALMEIDA, Ana Paula. Neuropsychological evaluation of Executive Functions: Methodological Considerations. Psychology: Reflection and Criticism, Rio Grande do Sul, v 22, n 3, 2009, p 366-393.

[14] KNAPP, Paul. Cognitive-Behavioral Therapy in Psychiatric Practice. Publisher: Artmed. Porto Alegre - RS, 2004, p. 212216.

[15] LURIA, Alexander Romanovich (Fundamentals of Neuropsychology. Translation of Juarez Aranha Ricardo - Rio de Janeiro: Technical and Scientific Books. Editor of the University of São Paulo, 1981, p. 25-47.

[16] MORAES, Camila; SILVA Niedja. Mental health and work relationships: How anxiety influences human behavior in the workplace. Article, 2015.

[17] NEUFELD, Carmem Beatriz; CAVENAGE, Carla Cristina. Cognitive conceptualization of case: a proposal of systematization from the clinical practice and the training of cognitive-behavioral therapists. Brazilian Journal of Cognitive Therapies. Volume $6 n^{\circ} 2,2010$.

[18] OLIVEIRA, Maria Inês Santana de. Cognitive-behavioral 
intervention in anxiety disorder: Case Report. Brazilian Journal of Cognitive Therapies, v. 7, n. 1, p.30-34, 2011.

[19] PROBST, E. R. The evolution of women in the labor market. Available from: <http://www.icpg.com.br/artigos/rev0205.pdf $>$. Accessed: 25 June. 2012. 